\title{
Ultrasonic irradiation control of silica fouling during membrane distillation process
}

\author{
Deyin Hou ${ }^{\mathrm{a}, \mathrm{b}, *}$, Lijuan Zhang ${ }^{\mathrm{c}}$, Changwei zhao ${ }^{\mathrm{a}, \mathrm{b}}$, Hua Fan ${ }^{\mathrm{d}}$, Jun Wang ${ }^{\mathrm{a}, \mathrm{b}, *}$, Hongjing Huang ${ }^{\mathrm{d}}$ \\ a Key Laboratory of Drinking Water Science and Technology, Research Center for Eco-Environmental Sciences, Chinese Academy of Sciences, Beijing 100085, PR China \\ ${ }^{b}$ Beijing Key Laboratory of Industrial Wastewater Treatment and Reuse, Research Center for Eco-Environmental Sciences, Chinese Academy of Sciences, Beijing 100085, PR China

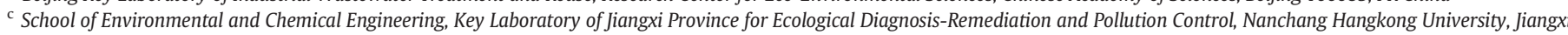 \\ 330063, PR China \\ ' School of Environmental and Chemical Engineering, Nanchang University, Jiangxi 330031, PR China
}

\section{H I G H L I G H T S}

- Ultrasonic irradiation was introduced into membrane distillation process.

- Influence of ultrasonic irradiation on silica fouling control was investigated.

- Calcium ion would destroy silica colloid stability and aggravate membrane fouling.

- Ultrasonic irradiation can mitigate silica fouling and maintain permeate flux.

\section{A R T I C L E I N F O}

\section{Article history:}

Received 19 November 2015

Received in revised form 18 February 2016

Accepted 25 February 2016

Available online 3 March 2016

\section{Keywords:}

Membrane distillation

Membrane fouling

Ultrasonic irradiation

Silica

Permeate flux

\begin{abstract}
A B S T R A C T
Ultrasonic irradiation was introduced into membrane distillation process and the influence of ultrasonic irradiation on silica fouling control was investigated. A gradual decline of permeate flux during the concentration process of silica solution was observed due to the formation and deposition of colloidal polysilicic acid on the membrane surface. The PTFE hollow fiber membrane could maintain its mechanical properties and initial pore size distribution in the presence of ultrasonic irradiation. Ultrasonic wave brought significant mechanical and thermal effects, and generated powerful shock wave and microstreaming with high speed. The microstreaming, shock wave and acoustic vortex streaming stimulated the liquid-membrane interface continuously, therefore the membrane surface could be effectively kept clean and the permeate flux was hardly affected by the increasing of concentration factor. Due to the charge neutralization and compression of double charged layer induced by calcium ions, the silica colloid stability was eliminated and the colloids aggregated. A large amount of silica scaling was deposited on the membrane surface even at the beginning of concentration process. With ultrasonic irradiation, the permeate flux maintained stable and was enhanced by about $43 \%$; the ultrasonic irradiation could effectively control silica fouling during membrane distillation.
\end{abstract}

(c) 2016 Elsevier B.V. All rights reserved.

\section{Introduction}

Membrane distillation (MD) is a thermal separation process using a hydrophobic membrane as separation media. Being different from conventional evaporation, MD can operate at relatively low temperatures and is thus able to tap into the vast amount of low-grade waste heat [1]. MD is also advantageous over conventional pressure-driven membrane processes, such as nanofiltration (NF) or reverse osmosis (RO), as its low operating pressure reduces the capital cost due to the absence

\footnotetext{
* Corresponding authors at: Key Laboratory of Drinking Water Science and Technology, Research Center for Eco-Environmental Sciences, Chinese Academy of Sciences, Beijing 100085, PR China.

E-mail addresses: dyhou@rcees.ac.cn (D. Hou), junwang@rcees.ac.cn (J. Wang).
}

of expensive components, such as high pressure pumps and vessels, as well as pressure exchangers [2]. According to the condensation method adopted, the MD systems can be classified into four different categories: direct contact membrane distillation (DCMD), air gap membrane distillation (AGMD), sweeping gas membrane distillation (SGMD) and vacuum membrane distillation (VMD) [3]. Among these four MD configurations, DCMD is the most studied and simplest in design and application [4], in which condensation steps carried out inside the membrane module, leading to a simple operation mode without the need of external condensers like those in SGMD and VMD.

Although there have been extensive studies on the application of MD for desalination, removal of organic matters in drinking water, treatment of wastewater and recovery of valuable components [5-9], the industrial implementation of MD is not yet feasible and significant advancements 
are still needed to reach the theoretical cost competitiveness and develop market share growth [10]. Membrane scaling in MD process is of particular importance, as scaling can alter membrane surface properties, change membrane pore structure, potentially lead to the wetting of membrane pores and ultimately cause a decline in membrane permeability [11]. Scaling of sparingly soluble salts such as $\mathrm{CaCO}_{3}, \mathrm{CaSO}_{4}$, and silicates has been identified as a cause of flux decline when recovering water from natural streams, including brines from desalination processes [12-15]. In recent years, a number of studies have investigated the effect of membrane scaling on the overall MD process utilizing different types of membranes such as flat-sheet and hollow fibers, as well as using different modules [4]. However, the majority of studies focused on the negative effects and mitigation strategies of inorganic membrane scaling such as calcium carbonate or calcium sulfate [16-18]. As far as we know, there are limited studies dedicated to silica scaling in the MD process.

Silica is generally found in water supplies in three different forms: reactive, colloidal and suspended particles [19]. Silica scaling has become a common problem in membrane separation processes due to its low solubility. The prevailing forms of silica are meta silicic acids as $\left(\mathrm{H}_{2} \mathrm{SiO}_{3}\right)_{\mathrm{n}}$ with low n numbers. Since silicic acid is a weak acid, it is mostly in the undissociated form at or below a neutral $\mathrm{pH}$. Supersaturated silicic acid can further polymerize to form insoluble colloidal silica or silica gel, which can cause membrane scaling [20]. Madaeni et al. [21] studied the silica fouling problem in the application of membranes for water treatment. The chemical cleaning of silica fouled membrane using acid, alkaline, chelating agent, surfactant and detergent solutions was investigated. It was found that cleaning efficiency depended on the type of cleaning agent and its concentration. The results showed that the efficiency increases with the increasing of chemical cleaning concentration while the mix cleaning solution of EDTA, SDS, and $\mathrm{NaOH}(0.05 \mathrm{wt} . \%)$ was the most effective solution for foulant removal. Although polymerized silica scales can be removed by a high $\mathrm{pH}$ cleaning solution ( $\mathrm{pH}$ of $10-11$ ), it will take many hours for sodium hydroxide solution to remove silica scale at the maximum pH allowed by membrane manufacturer [22]. Neofotistou and Demadis [23] applied antiscalant to mitigate silica fouling in desalination systems. The results showed that the $\mathrm{NH}_{2}$-terminated dendrimer polyaminoamide (PAMAM) was effective for $\mathrm{SiO}_{2}$ inhibitors with the optimum dosage. However, the dendrimers would form $\mathrm{SiO}_{2}$-PAMAM composite precipitates after a long period. Silica inhibitors can retard the polymerization of silica; Butt et al. [24] proposed that phosphonate-based chemicals acted as scale inhibitors in membrane systems. In addition, scale inhibitors such as high molecular weight polyacrylates were also used to increase the solubility of silica and to prevent silica scaling formation [25].

Ultrasonic wave is referred to the acoustic wave with the frequency between $20 \mathrm{kHz}$ and $10 \mathrm{MHz}$. Several concomitant effects, such as mechanics, thermotics and cavitation effect, during the propagation of ultrasonic wave in various media, have been recognized to be beneficial to many physical and chemical processes [26]. For membrane separation processes, the ultrasonic technique is used mainly in membrane fouling monitoring, membrane cleaning and membrane flux enhancement [27-31]. Li et al. [32-34] applied ultrasonic technique as a nondestructive, real-time, in situ measuring technique for direct monitoring of membrane fouling and cleaning during ultrafiltration (UF) and RO, and found that the ultrasonic technique was a useful technique for the non-destructive investigation of fouling and cleaning in membrane applications. Kobayashi et al. [35-39] introduced ultrasonic technique to create novel anti-fouling membrane processes for membrane water treatment; it was reported that ultrasonic irradiation during membrane filtration was very effective in removing foulants from membranes. Massive evidences exist that the ultrasonic effect is useful for water cleaning of fouled membrane; the ultrasonic cleaning offers advantages and is an effective method compared with other typical cleaning methods using physical and chemical methods [40-42].

The objective of this paper is to introduce ultrasonic irradiation into DCMD process to develop a novel ultrasonic assisted direct contact membrane distillation hybrid process and to investigate the influence of ultrasonic irradiation on silica scaling mitigation. Compared with traditional physical and chemical methods for scaling control, ultrasonic irradiation is expected to be a real-time, in situ technique and can also ensure MD system continuous operation without chemical addition and membrane drying.

\section{Experimental}

\subsection{Materials and membrane module}

The polytetrafluoroethylene (PTFE) hydrophobic hollow fiber membrane with a mean pore diameter of $0.26 \mu \mathrm{m}$, supplied by DD Water Group Co., Ltd. (China), was chosen to fabricate membrane modules. The SEM images of the PTFE membrane are shown in Fig. 1. The hollow fibers in the number of 40 pieces were assembled into a polyester tube (diameter $d_{\text {in }} / d_{\text {out }}=15 / 20 \mathrm{~mm} / \mathrm{mm}$ ) with two UPVC T-tubes and two ends of the bundle of fibers were sealed with solidified epoxy resin to compose a membrane module. The effective membrane length was $100 \mathrm{~mm}$ for each membrane module. The characteristics of the membrane and membrane modules are presented in Table 1.

\subsection{Ultrasonic assisted membrane distillation hybrid process}

The ultrasonic assisted membrane distillation experimental setup is schematically shown in Fig. 2. The hot feed stirred continually by a magnetic stirrer flowed through the shell side of the fibers, and the cold distillate with conductivity in the range of 22 to $25 \mu \mathrm{S} / \mathrm{cm}$ flowed through the lumen side. The initial volumes of the feed and the distillate were $4.0 \mathrm{~L}$ and $0.25 \mathrm{~L}$, respectively. Both solutions were circulated in the membrane module with the help of two magnetic pumps (MP-15RN, Shanghai Seisun Pumps, China). The feed and the distillate flowed co-currently through the module, and the circulation feed rate $\left(V_{f}\right)$ was $0.25 \mathrm{~m} / \mathrm{s}$, while the cold side $\left(V_{p}\right)$ being $1.0 \mathrm{~m} / \mathrm{s}$. The feed temperature $\left(T_{f \text {-inlet }}\right)$ was fixed at $53{ }^{\circ} \mathrm{C}$ by a Pt-100 sensor and a heater connected to an external thermostat (XMTD-2202, Yongshang Instruments, China). The distillate temperature $\left(T_{p \text {-inlet }}\right)$ kept at $20^{\circ} \mathrm{C}$ by a spiral glass heat exchanger immersed in the constant temperature trough of the cooler (SDC-6, Nanjing Xincheng Biotechnology, China). The temperature of both fluids was monitored at the inlet and outlet of the membrane module using four Pt-100 thermoresistances connected to a digital meter (Digit RTD, model XMT-808, Yuyao Changjiang Temperature Meter Instruments, China) with an accuracy of $\pm 0.1^{\circ} \mathrm{C}$. An electric conductivity monitor (CM-230A, Shijiazhuang Create Instrumentation Technologies, China) was used to monitor the distillate water quality.

In order to investigate the influence of ultrasonic irradiation on silica scaling mitigation, the membrane module was immersed vertically in a water bath $\left(15 \times 15 \times 42 \mathrm{~cm}^{3}\right)$ and transducers were adhered to the four outside surfaces of the water bath stainless steel shell. The ultrasonic bath was capable of generating ultrasonic with a frequency of $20 \mathrm{kHz}$ and an acoustic power of $260 \mathrm{~W}$. The ultrasonic irradiation device was supplied by Quanyi Electronic Equipment Co., Ltd. (Baoding, China).

\subsection{Experimental}

Certified analytical reagent grade $\mathrm{Na}_{2} \mathrm{SiO}_{3}$ and $\mathrm{CaCl}_{2}$ were supplied by Sinopharm Chemical Reagent Co., Ltd. (China). Silicate stock solution was prepared from sodium metasilicate and stored in a polyethylene bottle. The feed silica solution can be obtained by adding known volumes of silicate stock solution and water in the polyethylene container.

The feed silica solution concentration of $150 \mathrm{mg} / \mathrm{L}$ was expressed as $\mathrm{SiO}_{2}$ in this study, and its $\mathrm{pH}$ was adjusted to 7.0 using dilute hydrochloric acid before MD experiment. During MD process, no make-up water was added into the feed tank, indicating that the feed was gradually 

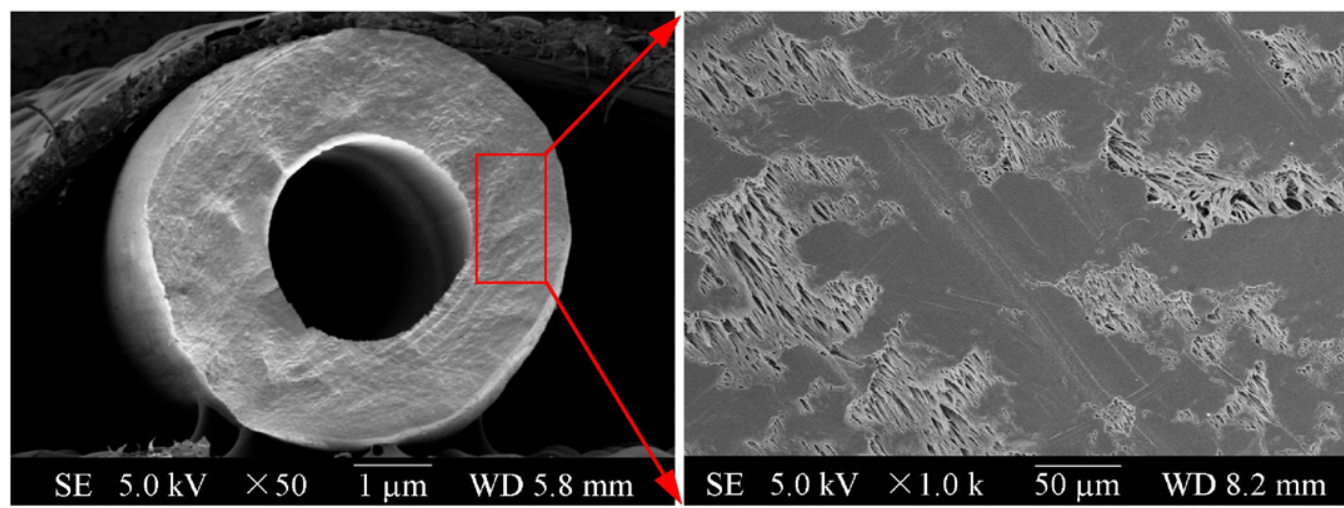

(a)

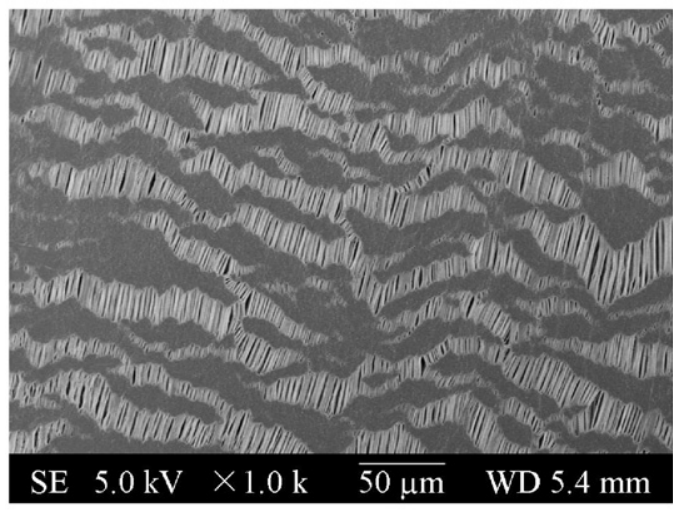

(b)

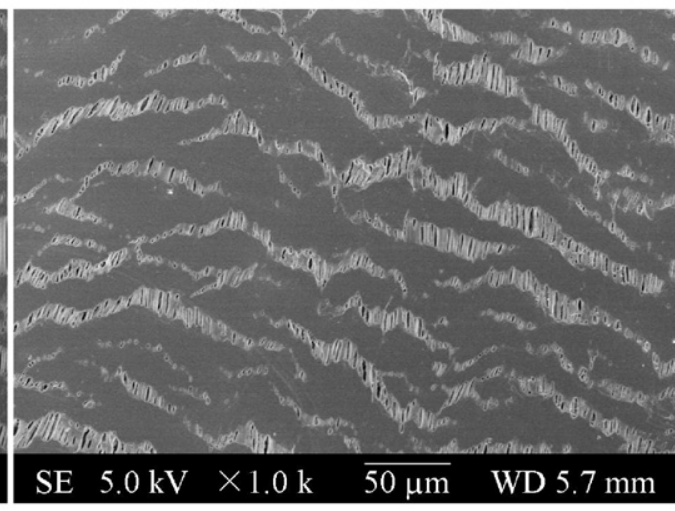

(c)

Fig. 1. SEM images of the PTFE membrane: (a) cross section, (b) inner surface, (c) outer surface.

concentrated. The concentration factor $K$ can be calculated by the following equation:

$K=\frac{Q_{0}}{Q_{o}-Q_{p}}$

where $Q_{o}$ is the initial quantity of feed $(\mathrm{kg})$ and $Q_{p}$ is the cumulative permeate production $(\mathrm{kg})$. The permeate flux $J$ was calculated by the following equation:

$J=\frac{\Delta W}{A \Delta t}$

where $J$ is the permeate flux $\left(\mathrm{kg} / \mathrm{m}^{2} \mathrm{~h}\right), \Delta W$ is the quantity of distillate $(\mathrm{kg}), A$ is the effective area of flat-sheet membrane $\left(\mathrm{m}^{2}\right)$ and $\Delta t$ is the sampling time (h). The relative permeate flux $J_{R}$ was used to describe

Table 1

The characteristics of the membrane material and the membrane module.

\begin{tabular}{ll}
\hline Membrane and module & Properties \\
\hline Membrane material & PTFE \\
Mean pore diameter $(\mu \mathrm{m})$ & 0.26 \\
Porosity (\%) & 45.07 \\
Inner diameter of hollow fiber $(\mathrm{mm})$ & 0.80 \\
Membrane thickness $(\mathrm{mm})$ & 0.39 \\
Number of hollow fibers & 40 \\
Effective membrane length $(\mathrm{mm})$ & 100 \\
Effective membrane area $\left(\mathrm{cm}^{2}\right)$ & 198.4 \\
\hline
\end{tabular}

the change of membrane permeability with the concentration factor increase:

$J_{R}=\frac{J}{J_{0}}$

where $J_{o}$ is the initial permeate flux $\left(\mathrm{kg} / \mathrm{m}^{2} \mathrm{~h}\right)$. When the concentration factor reached 4.0, the MD process was stopped, and a new membrane module was used for each experiment. Upon the completion of each experiment, the membrane was removed from the membrane module for further analysis and excess liquid on the membrane surface was allowed to drain off by gently tilting the hollow fiber.

\subsection{Membrane surface analysis}

The silica fouling on the membrane surface was observed by using a HITACHI S-3000N scanning electron microscope (SEM) (Hitachi Ltd., Japan). The fouled membranes were dried in a desiccator, and sputtered with platinum using a HITACHI E-1010 Ion Sputtering device for SEM observation. Elemental analysis of the fouled membrane surface was accomplished using an energy dispersive X-ray spectroscopy (EDS) detector. The fouled membrane samples were handled gently and without any excessive forces to ensure that the fouling remained intact.

\subsection{Membrane pore size distribution test}

Pore size distribution of the PTFE hollow fiber membrane was investigated by using a Capillary Flow Porometer (Porolux 1000, IB-FT GmbH, Germany). The fibers were fully wetted with a liquid named Porefil 


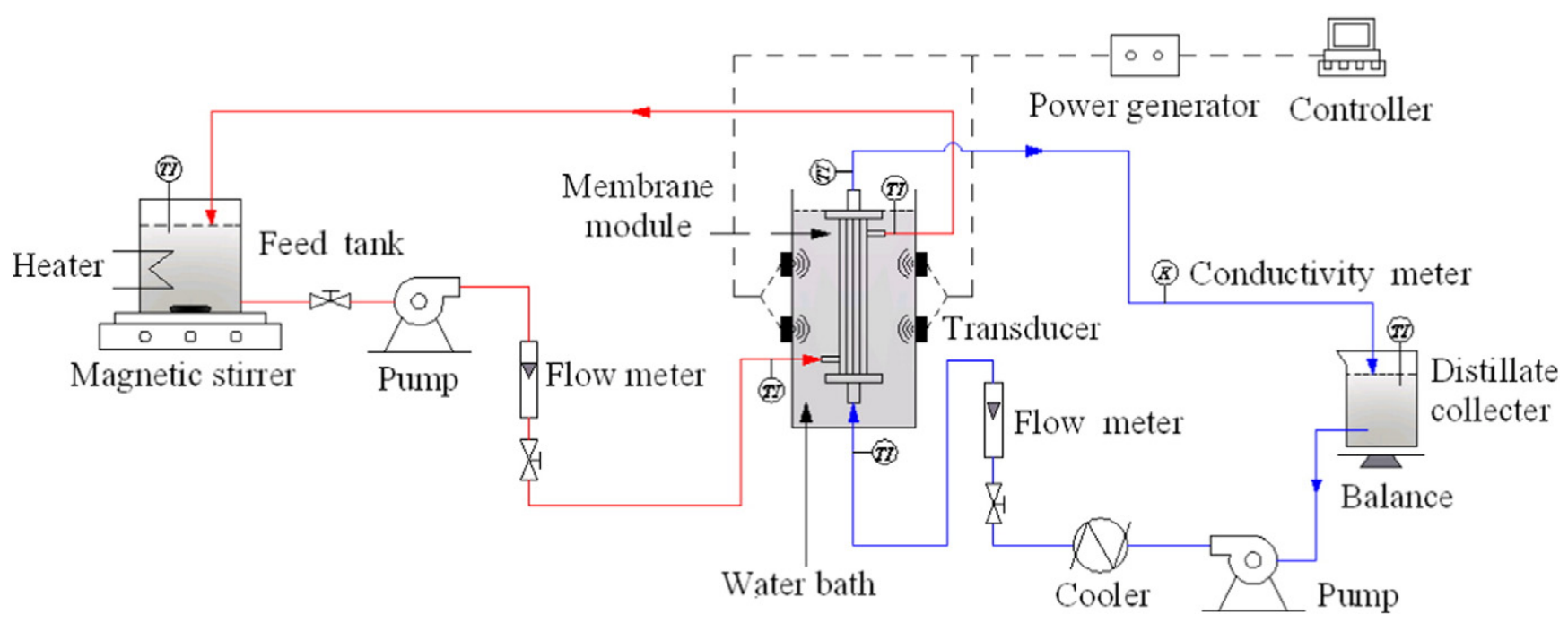

Fig. 2. Schematic diagram of ultrasonic assisted membrane distillation system.

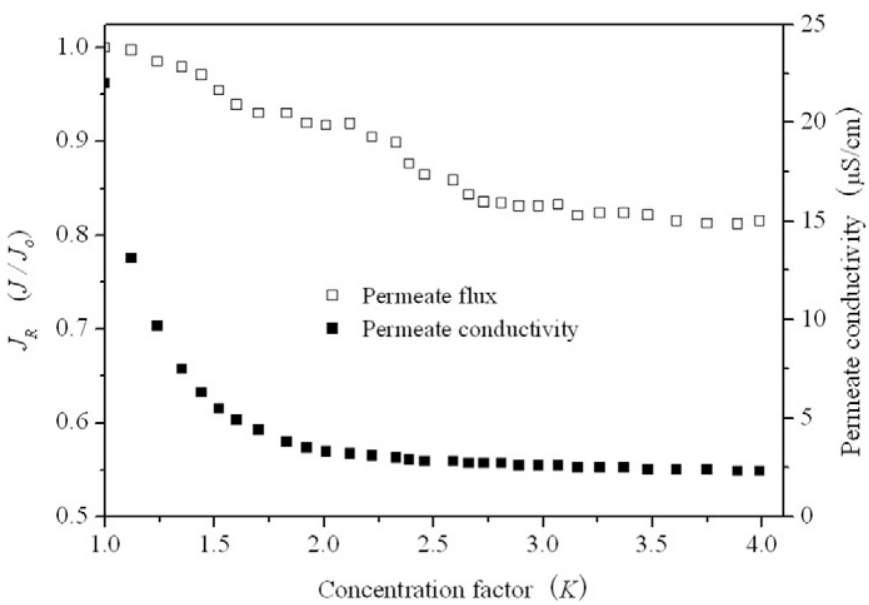

Fig. 3. The process of DCMD concentration of silica solution.

(supported by IB-FT, surface tension $16 \mathrm{dyn} / \mathrm{cm}$ ), and then the measurements were carried out following the procedure described in literature [43]. The pore size distribution was determined with the aid of the computer software coupled to CFP.

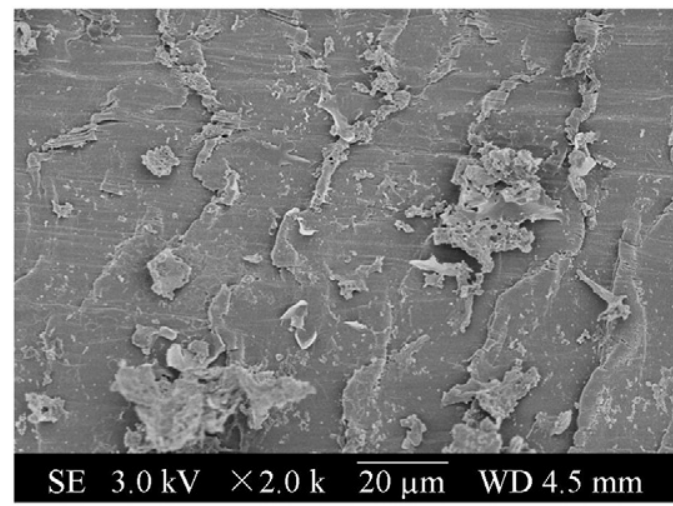

(a)

\subsection{Mechanical property analysis}

Mechanical properties of the PTFE hollow fiber membrane were measured with an Instron tensiometer (Instron 5565-5 kN, Instron Corporation, USA) at room temperature. The hollow fiber sample was clamped at both ends and pulled in tension at a constant elongation rate of $10 \mathrm{~mm} / \mathrm{min}$ with an initial length of $20 \mathrm{~cm}$, and five specimens were tested for each sample.

\subsection{Particle size measurement}

The particle size in feed was measured using an online laser particle analyzer (GR-1501, Green Technology, China). The range of detection of the particle analyzer is $15-4000 \mu \mathrm{m}$. The estimated error on particle size measurement itself is less than $2 \%$. The precision of the measurements was assessed on a test bench, by quantifying the standard deviation of a series of measurements. It was lower than $1.5 \%$. The volume-mean diameter of the particle in feed was determined by five time analyses.

\subsection{Zeta potential measurement}

The measurements of zeta potential of silica colloid were conducted at a fixed temperature of $53{ }^{\circ} \mathrm{C}$ to operate within controllable laboratory conditions. The zeta potential was determined with a Zetasizer 2000 zeta potential analyzer (Malvern Co., Malvern Town, U.K.). For each

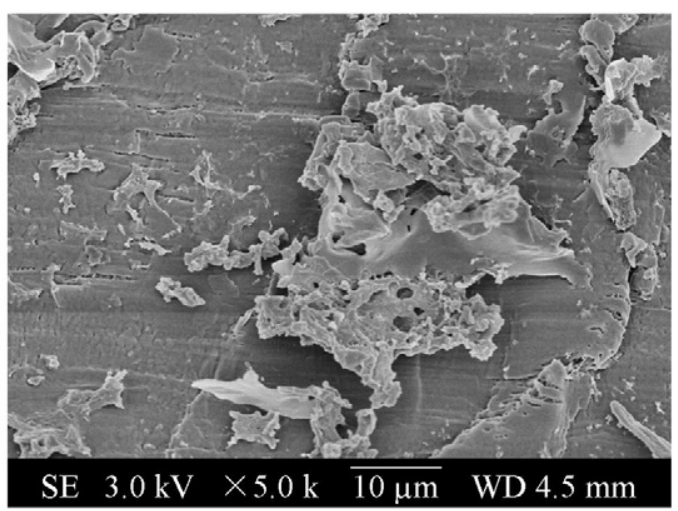

(b)

Fig. 4. Morphological image of the PTFE membrane after silica solution concentration experiment: (a) $2000 \times$ and (b) $5000 \times$. 


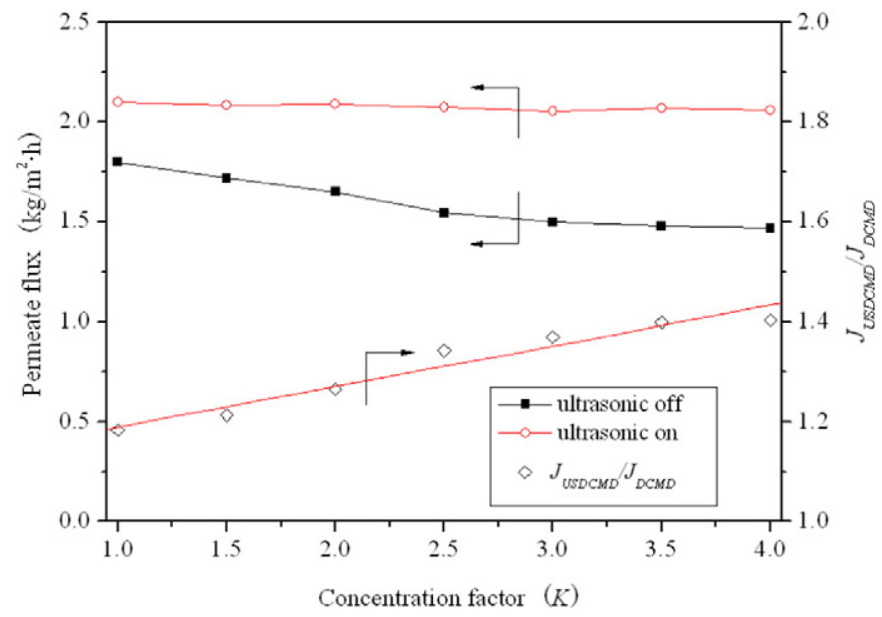

Fig. 5. Effect of ultrasound irradiation on the permeate flux during silica solution concentration.

zeta potential measurement, about $1.5 \mathrm{~mL}$ of the silica solution with different concentration factors was poured into a $4.0 \mathrm{~mL}$ plastic cuvette, then a palladium electrode pair was immersed in the tested sample and the zeta potential was obtained by measuring at least three samples. After each measurement, the samples were poured back to the feed tank to guarantee the concentration factor accuracy.

\section{Results and discussions}

\subsection{Concentration of silica solution}

The initial concentration of the feed silica solution used in DCMD concentration process was $150 \mathrm{mg} / \mathrm{L}$. The permeate flux as a function of concentration factor is illustrated in Fig. 3. A gradual decline of permeate flux was observed with the increasing of concentration factor. When the concentration factor reached 4.0 , the permeate flux decreased by about $20 \%$ compared with the initial permeate flux.

Silica exists in many crystalline and amorphous forms. The solubility of crystalline silica in water is very low (on the order of $6 \mathrm{mg} / \mathrm{L} \mathrm{SiO}{ }_{2}$ ). By contrast, amorphous silica has a much higher solubility in the range of 100 to $140 \mathrm{mg} / \mathrm{L} \mathrm{SiO}_{2}$. The potential for silica scaling increases when the dissolved silica in an aqueous system exceeds the amorphous silica solubility limit. In water, silica forms silicic acid. During the concentration process of silica solution, the silicic acid underwent basecatalyzed polymerization resulting in the formation and deposition of

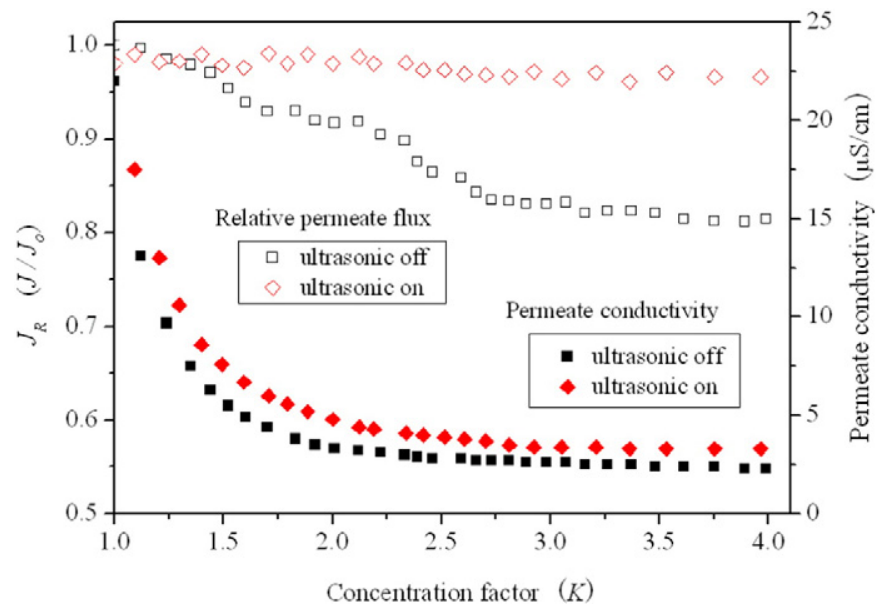

Fig. 6. Effect of ultrasound irradiation on the process of DCMD concentration of silica solution.

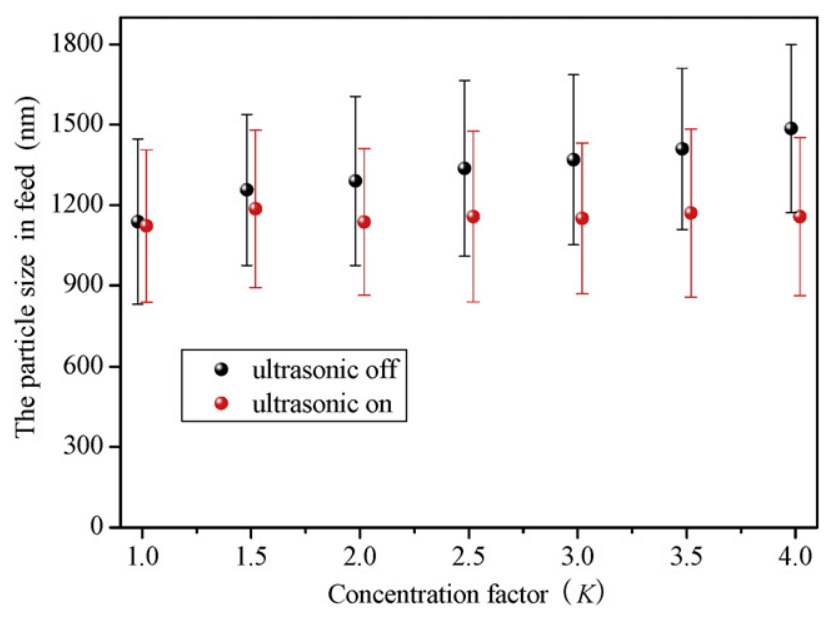

Fig. 7. Effect of ultrasound irradiation on the particle size of silica in feed.

colloidal polysilicic acid on the membrane surface. The deposited colloids would form a gel layer and cover part of the membrane surface, which subsequently led to permeate flux decline.

The images of the PTFE membrane fouled with the $\mathrm{SiO}_{2}$ scaling at the end of the experiment are shown in Fig. 4, and the SEM analysis confirmed an amorphous silica scaling layer on the membrane surface.

\subsection{Ultrasonic irradiation effect on DCMD of silica solution}

The effect of ultrasonic irradiation on the absolute permeate flux and relative permeate flux is shown in Figs. 5 and 6, respectively. It can be seen that the permeate flux was hardly affected by the increasing of concentration factor in the presence of ultrasonic irradiation. When the concentration factor reached 4.0 , the relative permeate flux declined insignificantly and maintained about $97 \%$ with the ultrasonic irradiation. The increase of the ratio of membrane permeate flux with and without ultrasonic irradiation (JUSDCMD/J $J_{\text {DCMD }}$ ) with the increasing of the concentration factor as shown in Fig. 5 indicated that the higher the concentration factor was, the more obvious the ultrasonic enhancement of permeate flux. When the concentration factor varied from 1.0 to 4.0 , the ratio of permeate flux with and without ultrasonic irradiation enhanced from 1.18 to 1.40 .

Although the particle sizes of silica in feed increased with the increase of concentration factor in the absence of ultrasonic irradiation, the ultrasonic irradiation could maintain the particle size constant as shown in Fig. 7. Ultrasonic irradiation could mitigate membrane scaling caused by silica colloids and prevent the permeate flux decline, which could be mainly attributed to the cleaning effect of ultrasonic to the membrane surface. The schematic illustration of the ultrasonic irradiation effect on mitigation of silica scaling deposition on the membrane surface was given in Fig. 8. Ultrasonic wave can bring significant mechanical and thermal effects, and generate powerful shock wave and microstreaming with high speed. The microstreaming, shock wave and acoustic vortex streaming can continuously stimulate the liquidmembrane interface, therefore refreshed the interface and prevented the deposition of silica scaling. In addition, the mechanical effect promotes turbulence, which reduces the temperature polarization and concentration polarization. As a result, the likelihood of crystallization was also mitigated by the lower silica concentration in the boundary layer.

In the presence of ultrasonic irradiation, the surface of the PTFE membrane was much cleaner compared with that of no ultrasonic irradiation as shown in Fig. 9. The SEM images of the PTFE membrane surface demonstrated that the ultrasonic irradiation can effectively mitigate the membrane scaling caused by silica colloids in some extent. 


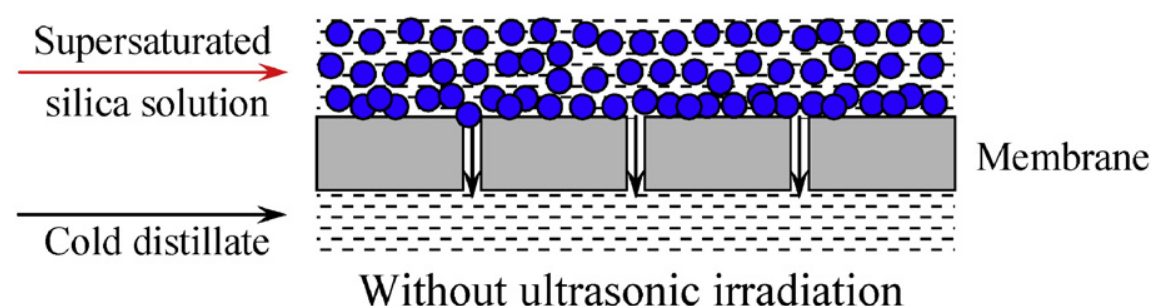

Without ultrasonic irradiation

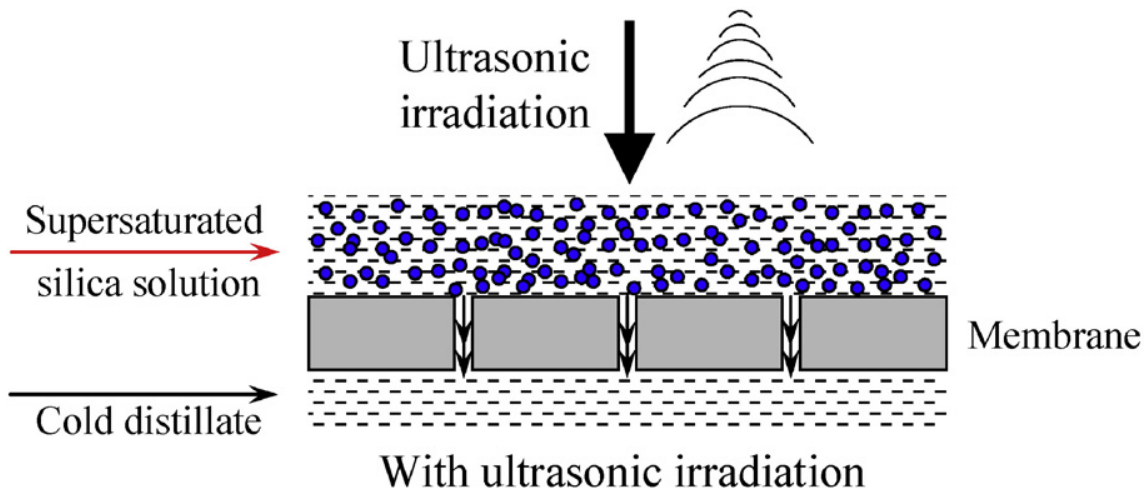

Fig. 8. Schematic illustration of ultrasonic irradiation effect on mitigation of silica scaling.

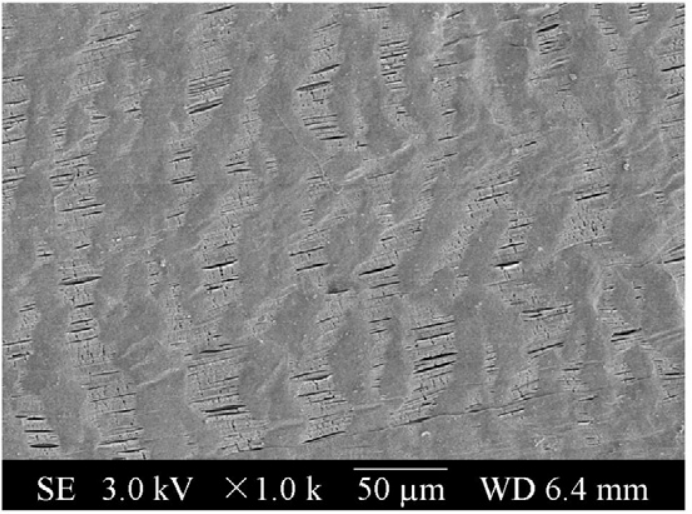

(a)

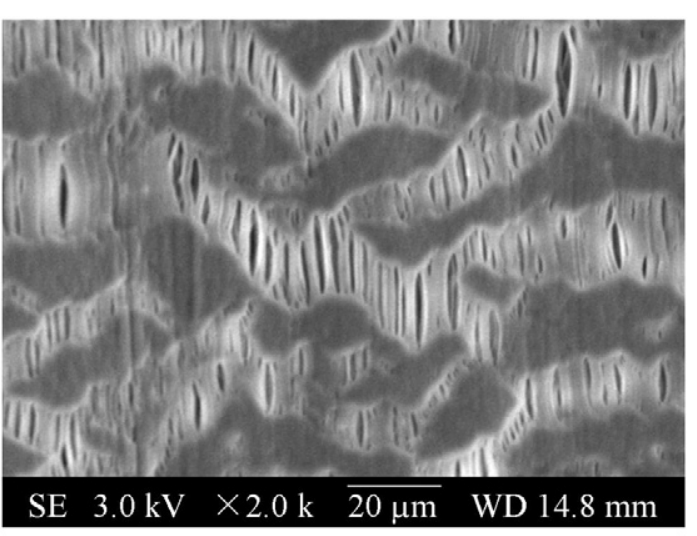

(b)

Fig. 9. Morphological image of the PTFE membrane after silica solution concentration with ultrasonic irradiation: (a) $1000 \times$ and (b) $2000 \times$.

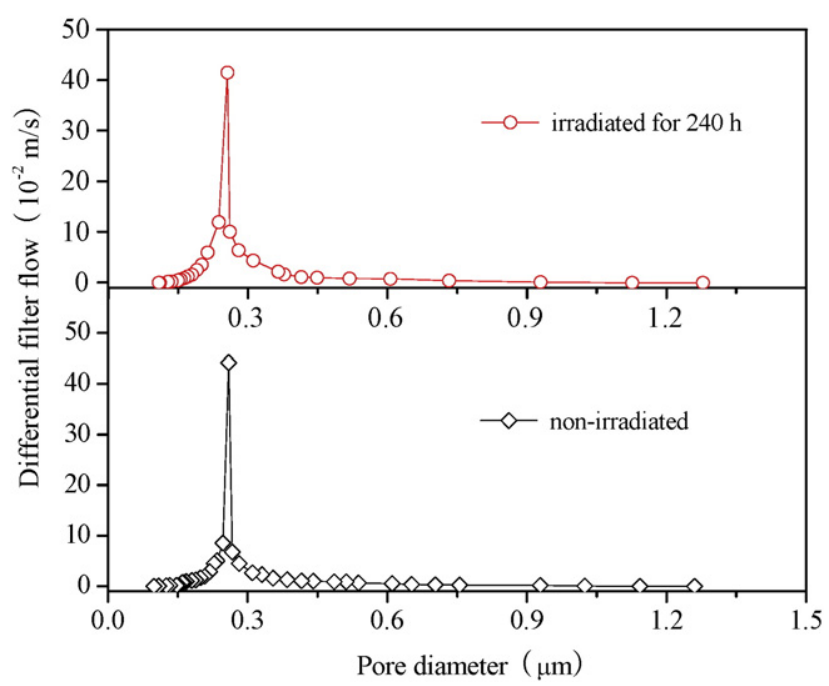

Fig. 10. The influence of ultrasonic irradiation on pore size distribution of the PTFE hollow fiber membrane.

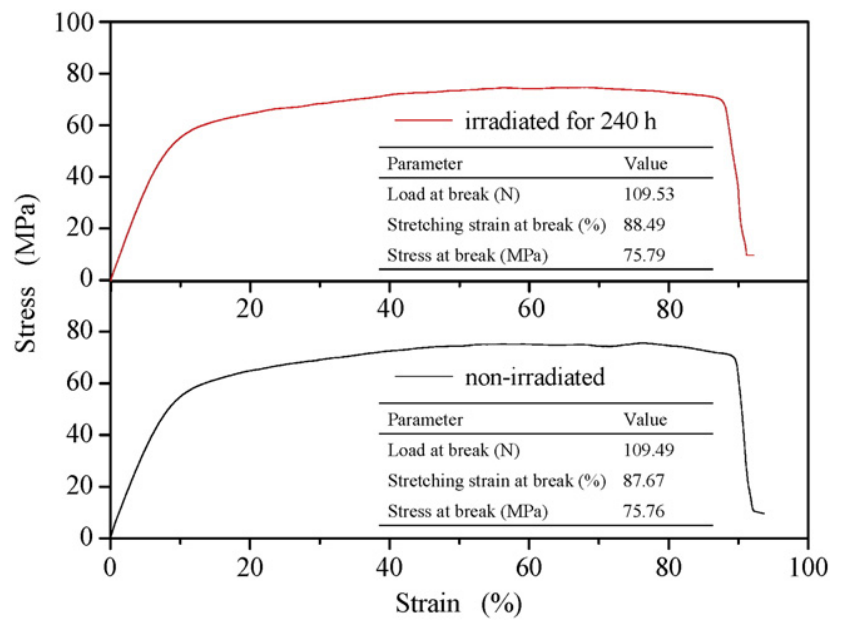

Fig. 11. The influence of ultrasonic irradiation on mechanical properties of the PTFE hollow fiber membrane. 


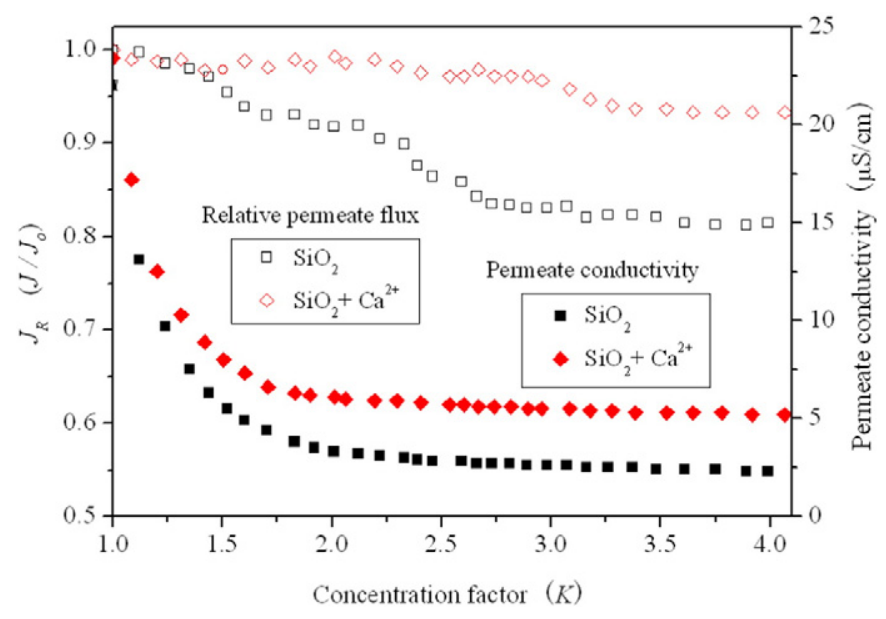

Fig. 12. Effect of calcium ion on the process of DCMD concentration of silica solution.

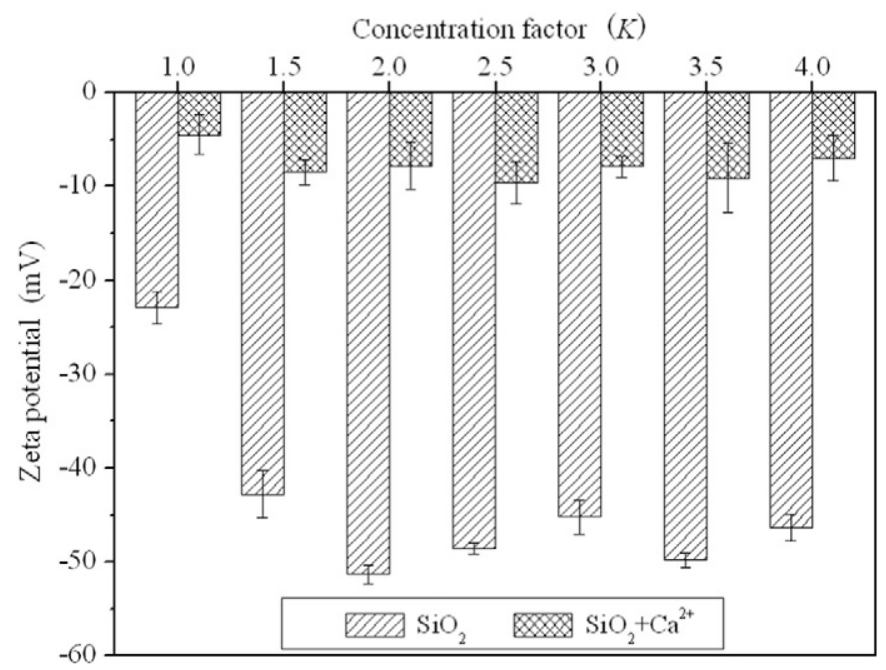

Fig. 13. Effect of ultrasound irradiation on the zeta potential of the silica colloids.

As shown in Fig. 6, the permeate conductivity declined with concentration factor increasing in the presence of ultrasonic irradiation, which indicated that the PTFE membrane rejection maintained almost $100 \%$ and ultrasonic irradiation did not destroy the membrane separation properties. However, it was necessary to check mechanical stability and pore size distribution of the PTFE hollow fiber during long term exposure to the ultrasonic. The PTFE hollow fiber membranes were immersed in an ultrasonic bath with an ultrasonic power at $260 \mathrm{~W}$ and frequency at $20 \mathrm{kHz}$, and the temperature of water bath was controlled at constant $53{ }^{\circ} \mathrm{C}$. After $240 \mathrm{~h}$ exposure to the ultrasonic, the pore size distribution and mechanical properties of the PTFE membrane are shown in Figs. 10 and 11, respectively. The mean pore diameter was $0.26 \mu \mathrm{m}$ and the largest pore diameter was $1.27 \mu \mathrm{m}$; the $240 \mathrm{~h}$ ultrasonic irradiation could not reduce or enlarge the membrane pores. In Fig. 11, it can be clearly seen that the stress-strain curves of the PTFE hollow fibers before and after being exposed in ultrasonic field almost coincide with each other. All of the test results demonstrated that the PTFE hollow fiber can be used in ultrasonic assisted direct contact membrane distillation hybrid process.

\subsection{The effect of calcium ion}

Calcium ion is a major cation in natural and waste waters, thus, the effect of calcium ion was studied in the present paper. The effect of the divalent cation $\mathrm{Ca}^{2+}$ in silica solution concentration is shown in Fig. 12, and the initial feed solution contained $150 \mathrm{mg} / \mathrm{L}$ silica and $20 \mathrm{mM} \mathrm{CaCl}_{2}$. Being greatly different from the DCMD of pure silica solution, the results reveal that the relative permeate flux declined slightly, with the relative permeate flux $J / J_{o}$ of 0.93 at the end of the concentration experiment when the salt $\mathrm{CaCl}_{2}$ was added into the silica solution. However, the initial permeate flux $J_{o}$ for the silica solution with calcium ion was $1.41 \mathrm{~kg} / \mathrm{m}^{2} \cdot \mathrm{h}$, which is much smaller than that of the silica solution without calcium ion, and the initial permeate flux $J_{o}$ for the pure silica solution was about $1.80 \mathrm{~kg} / \mathrm{m}^{2} \cdot \mathrm{h}$.

When dissolved in water, silica forms silica colloid. According to the flocculation theory, the divalent cation $\mathrm{Ca}^{2+}$ is counter-ion and the addition of calcium ions results in declining of the thickness of the diffuse layer. Therefore, the zeta potential of the silica colloids approaches neutral as shown in Fig. 13 and the zeta potential of the silica colloid was in the range of $-4.5 \mathrm{mV}$ to $-9.6 \mathrm{mV}$ in the presence of the divalent cation $\mathrm{Ca}^{2+}$. It has been reported that if the zeta potential is greater than $+30 \mathrm{mV}$ or less than $-30 \mathrm{mV}$, the colloid is stable [44]. Due to the charge neutralization and compression of double charged layer induced by calcium ions, the silica colloid stability was eliminated and the colloids aggregated. For this reason, a large amount of silica scaling would deposit on the membrane surface even at the beginning of DCMD concentration process as presented in Fig. 14. The deposited colloids formed a gel layer and cover most part of the membrane surface, which induced a smaller original permeate flux. Because the silica scaling formed in the original solution before starting of concentration, the continuous concentration of the feed solution did not cause a significant permeate flux decline. However, after all, the feed concentration

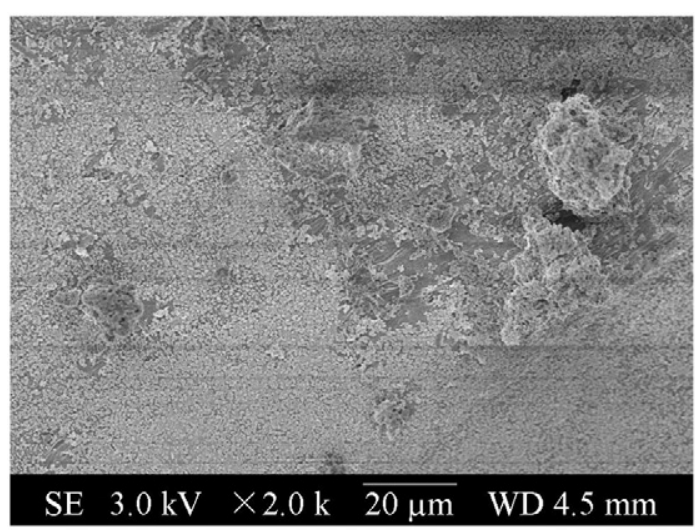

(a)

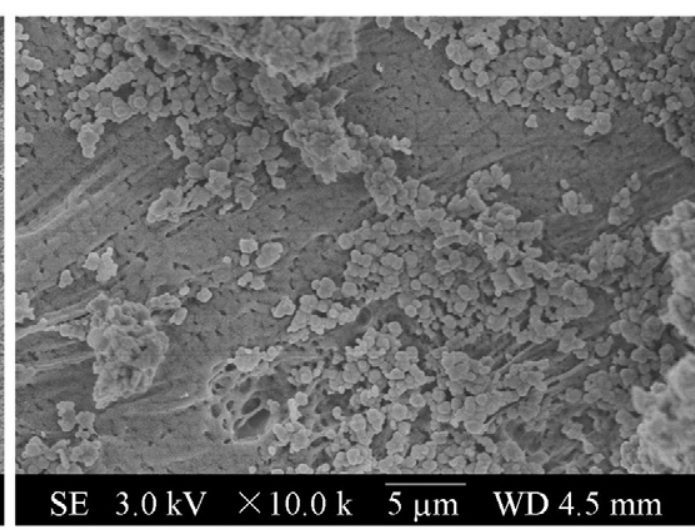

(b)

Fig. 14. Morphological image of the PTFE membrane after silica solution concentration running 30 min in the presence of calcium ion: (a) $2000 \times$ and (b) $10,000 \times$. 


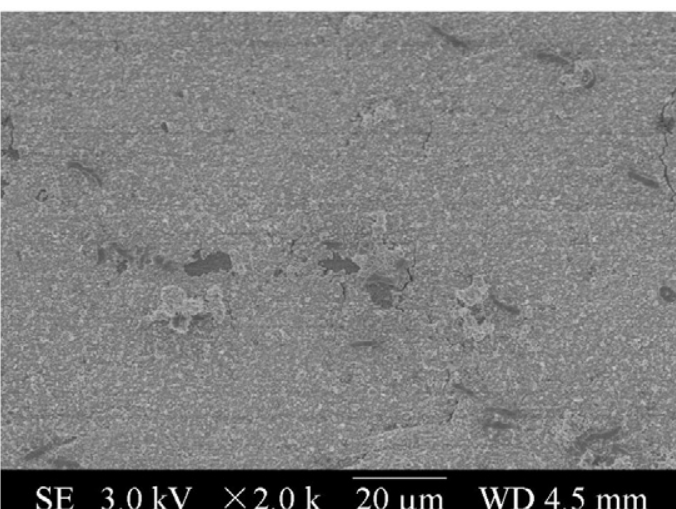

(a)

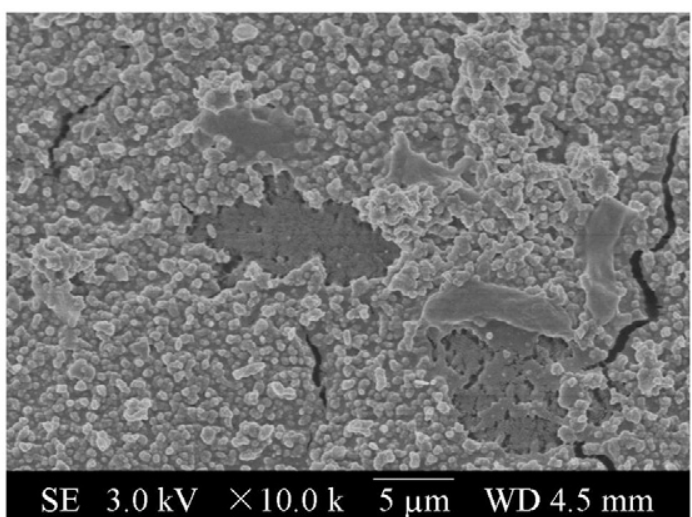

(b)

Fig. 15. Morphological image of the PTFE membrane after silica solution concentration experiment in the presence of calcium ion: (a) $2000 \times$ and (b) $10,000 \times$.

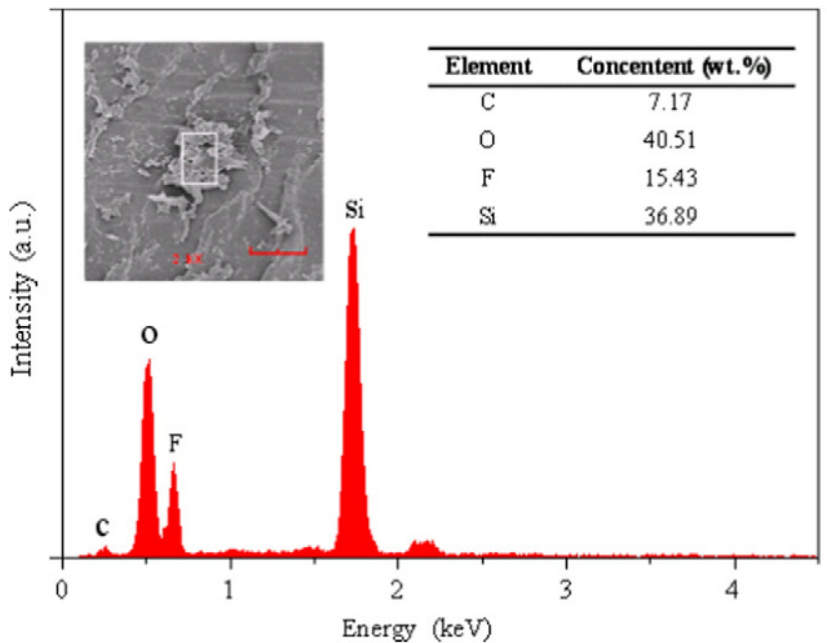

(a)

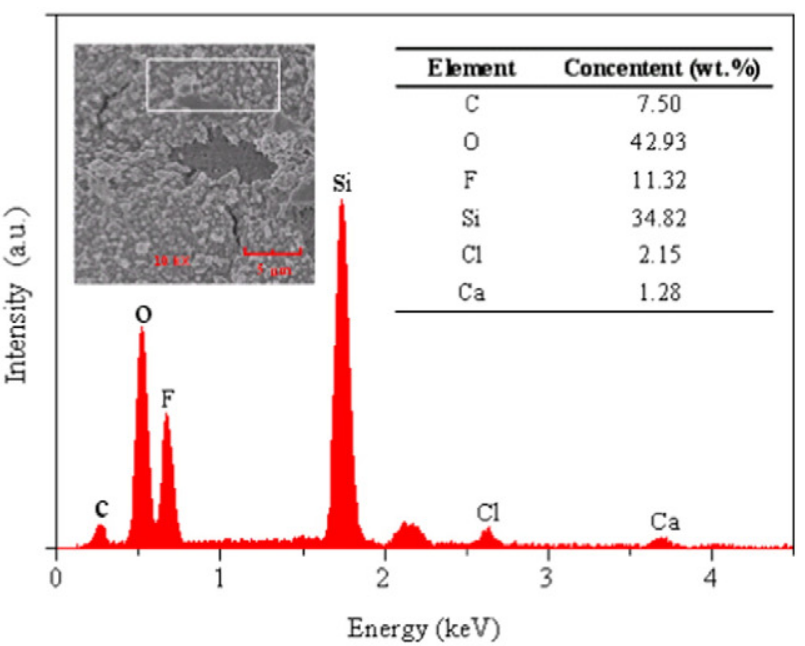

(b)

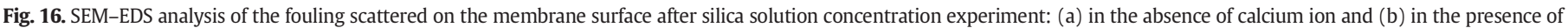
calcium ion.

increased with the concentration factor increasing, which would further aggravate membrane fouling. As can be seen from Fig. 15, almost all the membrane surface was covered by a thicker and compacter gel layer when the concentration factor reached 4.0 , and the permeate flux declined to about $1.30 \mathrm{~kg} / \mathrm{m}^{2} \cdot \mathrm{h}$.

The SEM-EDS analysis presented in Fig. 16 revealed that the deposit on the membrane surface mainly consisted of silica particles for pure silica solution concentration. When the divalent cation $\mathrm{Ca}^{2+}$ was added into the feed solution, the scaling covered membrane surface was the complex formed by $\mathrm{SiO}_{2}$ and a small amount of divalent cation $\mathrm{Ca}^{2+}$.

\subsection{Ultrasonic irradiation effect on silica scaling mitigation}

To investigate the influence of ultrasonic irradiation on silica fouling, DCMD concentration of the feed containing $150 \mathrm{mg} / \mathrm{L}$ silica and $20 \mathrm{mM}$ $\mathrm{CaCl}_{2}$ was carried out in the presence of ultrasonic irradiation. Except for the additional ultrasonic irradiation, other operating parameters were in accordance with the previous experiments. The result of the mixed solution concentration with ultrasonic irradiation is shown in Fig. 17.

Compared with the DCMD process in the absence of ultrasonic irradiation, the relative permeate flux maintained stable in the DCMD process with ultrasonic irradiation. Although the difference of the relative permeate flux between DCMD processes with and without ultrasonic irradiation was not noticeable, the absolute permeate flux was enhanced remarkably due to ultrasonic irradiation as shown in Fig. 18. The initial permeate flux was about $2.0 \mathrm{~kg} / \mathrm{m}^{2} \cdot \mathrm{h}$ with ultrasonic

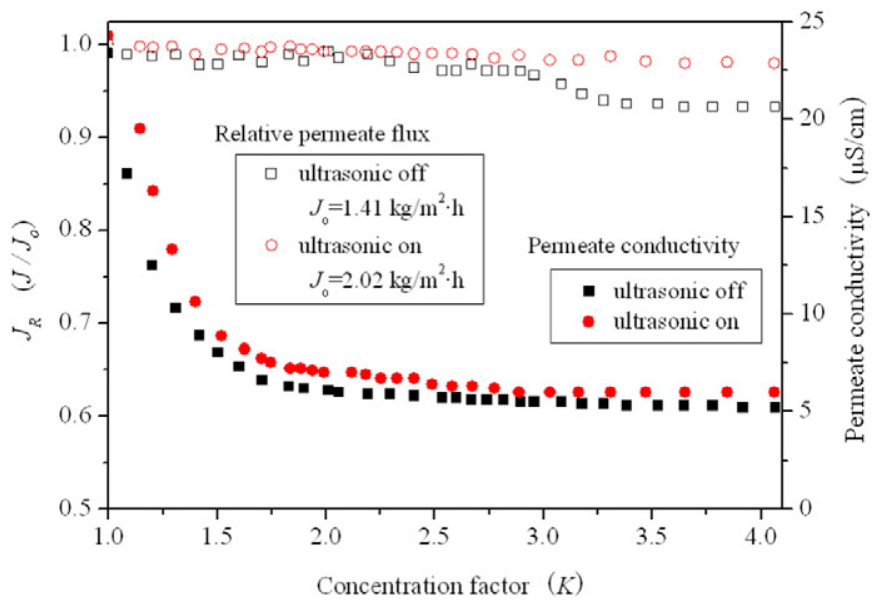

Fig. 17. Effect of ultrasound irradiation on the process of DCMD concentration of silica solution containing calcium ion. 


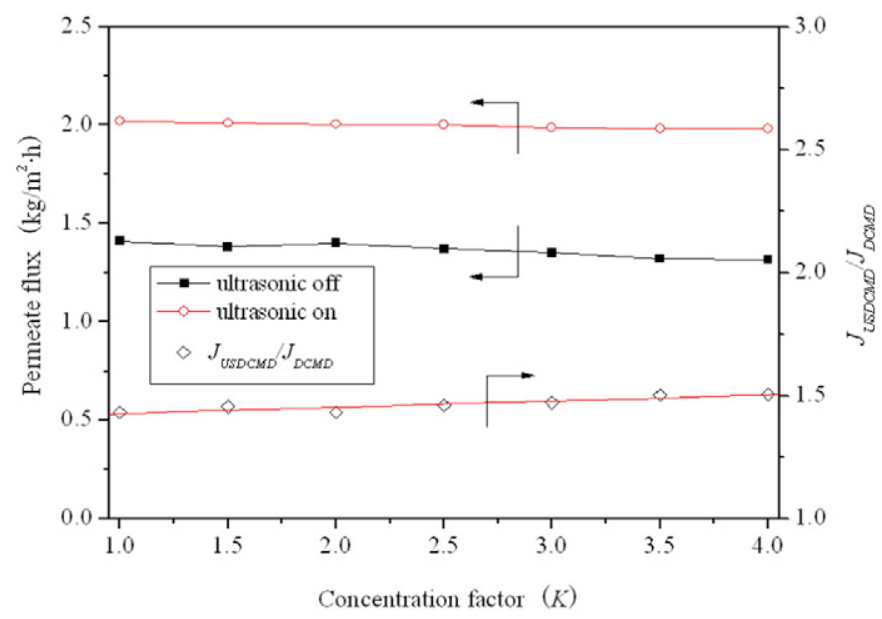

Fig. 18. Effect of ultrasound irradiation on the permeate flux during silica solution concentration.

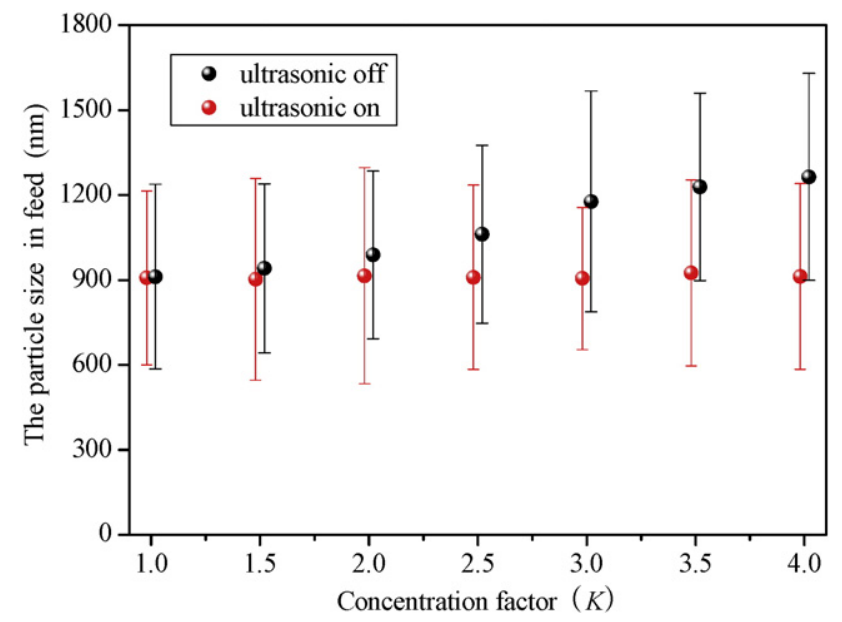

Fig. 19. Effect of ultrasound irradiation on the particle size in feed.

irradiation, about $43 \%$ more than that in the DCMD process without ultrasonic irradiation. The higher the concentration factor was, the more obvious the ultrasonic enhancement of permeate flux could be obtained. When the concentration factor reached 4.0 , the relative permeate flux declined a little and maintained about $98 \%$ with the ultrasonic irradiation and the ratio of membrane permeate flux with and without

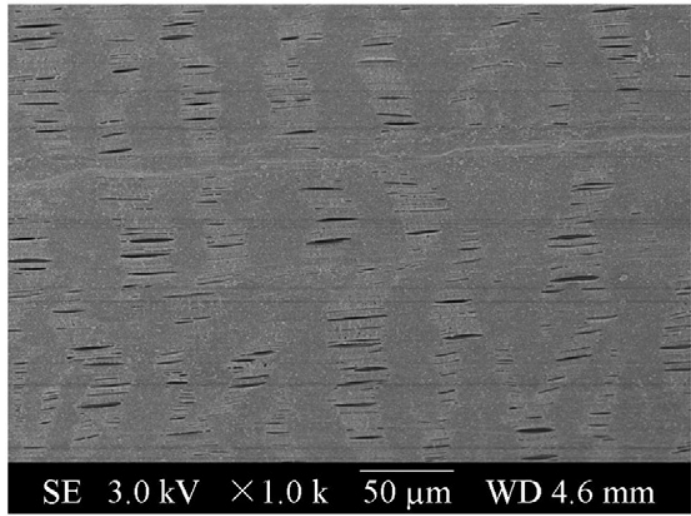

(a) ultrasonic irradiation (JUSDCMD/J J dition, in the presence of ultrasonic irradiation, the particle size in the feed can keep constant with the increasing of concentration factor as shown in Fig. 19. This can be mainly attributed to the mechanical effects induced by ultrasonic irradiation.

The ultrasonic irradiation can effectively mitigate the silica fouling, which can be observed from the images of membrane surface morphology. The difference between the surface morphologies of the membranes fouled with silica in the absence and presence of ultrasonic irradiation can be found by comparing Figs. 15 and 20. It can be clearly found that in the presence of ultrasonic irradiation, although there were some particles scattered on the membrane surface, there was no overall fouling layer covered on the membrane surface and the foulants were scattered and not as a whole, so the hydrophobic membrane was still porous and most of the membrane pores kept open. The experimental results demonstrated that it was possible that a large part of the membrane surface maintained clean in the presence of ultrasonic irradiation.

\section{Conclusions}

Although ultrasonic irradiation has been successfully applied to enhance the performance of pressure-driven membrane separation process such as UF, NF and RO, relatively few investigations have been carried out with the use of ultrasonic to mitigate silica scaling in MD process. In the present work, ultrasonic irradiation was introduced into membrane distillation process to develop a novel ultrasonic assisted direct contact membrane distillation hybrid process and the influence of ultrasonic irradiation on silica fouling control was investigated.

A gradual decline of permeate flux was observed during the concentration process of silica solution due to the formation and deposition of colloidal polysilicic acid on the membrane surfaces. Ultrasonic wave brought significant mechanical and thermal effects, and generated powerful shock wave and microstreaming with high speed; the mechanical effect promoted turbulence and reduced the concentration polarization in the boundary layer adjacent to the membrane surface. The microstreaming, shock wave and acoustic vortex streaming stimulated the liquid-membrane interface continuously, therefore, in the presence of ultrasonic irradiation, the membrane surface could be effectively kept clean and the permeate flux was hardly affected by the increasing of concentration factor.

Due to the charge neutralization and compression of double charged layer induced by calcium ions, the presence of divalent cation $\mathrm{Ca}^{2+}$ would cause the zeta potential of the silica colloids to be neutral, and the silica colloid stability was eliminated and the colloids aggregated. A large amount of silica scaling was deposited on the

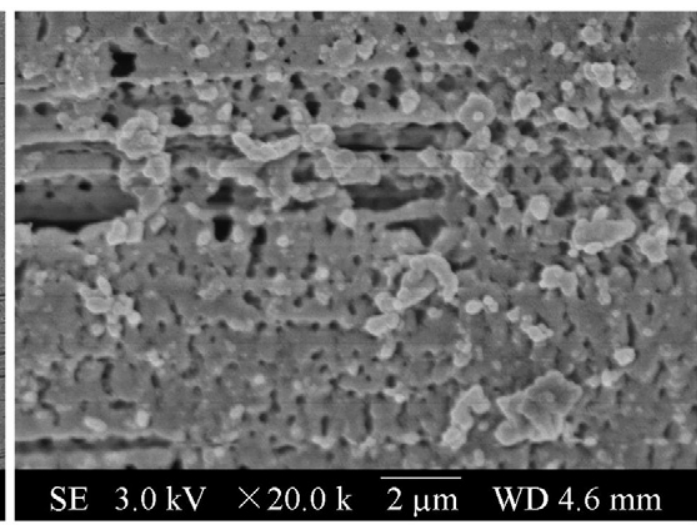

(b) 
membrane surface even at the beginning of concentration process. The deposited colloids formed a gel layer and cover most part of the membrane surface, resulting in a smaller original permeate flux; the continuous concentration of the silica solution did not cause a significant permeate flux decline with the increasing of concentration factor. Compared with the membrane distillation process without ultrasonic irradiation, the relative permeate flux maintained stable and the initial permeate flux was enhanced about $43 \%$. After MD process, most part of the membrane surface maintained clean, and the ultrasonic irradiation could effectively mitigate silica fouling.

\section{Acknowledgments}

Financial support provided by the National Natural Science Foundation of China (No. 51478454) and the special fund from the State Key Laboratory of Environmental Aquatic Chemistry (No. 13Z04ESPCT) are gratefully acknowledged.

\section{References}

[1] A.M. Alklaibi, N. Lior, Membrane-distillation desalination: status and potential, Desalination 171 (2005) 111-131.

[2] S.H. Lin, S. Nejati, C. Boo, Y.X. Hu, C.O. Osuji, M. Elimelech, Omniphobic membrane for robust membrane distillation, Environ. Sci. Technol. Lett. 1 (2014) 443-447.

[3] D.Y. Hou, J. Wang, D. Qu, Z.K. Luan, X.J. Ren, Fabrication and characterization of hydrophobic PVDF hollow fiber membranes for desalination through direct contact membrane distillation, Sep. Purif. Technol. 69 (2009) 78-86.

[4] M.S. El-Bourawi, Z. Ding, R. Ma, M. Khayet, A framework for better understanding membrane distillation separation process, J. Membr. Sci. 285 (2006) 4-29.

[5] A. Alkhudhiri, N. Darwish, N. Hilal, Produced water treatment: application of air gap membrane distillation, Desalination 309 (2013) 46-51.

[6] F. Banat, S. Al-Asheh, M. Qtaishat, Treatment of waters colored with methylene blue dye by vacuum membrane distillation, Desalination 174 (2005) 87-96.

[7] M. Gryta, K. Karakulski, The application of membrane distillation for the concentration of oil-water emulsions, Desalination 121 (1999) 23-29.

[8] A. Criscuoli, J. Zhong, A. Figoli, M.C. Carnevale, R. Huang, E. Drioli, Treatment of dye solutions by vacuum membrane distillation, Water Res. 42 (2008) 5031-5037.

[9] P.P. Zolotarev, V.V. Ugrozov, I.B. Volkina, V.M. Nikulin, Treatment of waste water for removing heavy metals by membrane distillation, J. Hazard. Mater. 37 (1994) $77-82$.

[10] M.M. Teoh, T.S. Chung, Membrane distillation with hydrophobic macrovoid-free PVDF-PTFE hollow fiber membranes, Sep. Purif. Technol. 66 (2009) 229-236.

[11] L.D. Tijing, Y.C. Woo, J.S. Choi, S. Lee, S.H. Kim, H.K. Shon, Fouling and its control in membrane distillation-a review, J. Membr. Sci. 475 (2015) 215-244.

[12] M. Gryta, Fouling in direct contact membrane distillation, J. Membr. Sci. 325 (2008) 383-394.

[13] J. Gilron, Y. Ladizansky, E. Korin, Silica fouling in direct contact membrane distillation, Ind. Eng. Chem. Res. 52 (2013) 10521-10529.

[14] E. Curcio, X. Ji, G. Di Profio, S. Al Obaidani, E. Fontananova, E. Drioli, Membrane distillation operated at high seawater concentration factors: role of the membrane on $\mathrm{CaCO}_{3}$ scaling in presence of humic acid, J. Membr. Sci. 346 (2010) 263-269.

[15] F. He, K.K. Sirkar, J. Gilron, Studies on scaling of membranes in desalination by direct contact membrane distillation: $\mathrm{CaCO}_{3}$ and mixed $\mathrm{CaCO}_{3} / \mathrm{CaSO}_{4}$ systems, Chem. Eng. Sci. 64 (2009) 1844-1859.

[16] F. He, K.K. Sirkar, J. Gilron, Effects of antiscalants to mitigate membrane scaling by direct contact membrane distillation, J. Membr. Sci. 345 (2009) 53-58.

[17] F. He, J. Gilron, H.Y. Lee, L.M. Song, K.K. Sirkar, Potential for scaling by sparingly soluble salts in crossflow DCMD, J. Membr. Sci. 311 (2008) 68-80.

[18] L.D. Nghiem, T. Cath, A scaling mitigation approach during direct contact membrane distillation, Sep. Purif. Technol. 80 (2011) 315-322.

[19] P. Sahachaiyunta, T. Koo, R. Sheikholeslami, Effect of several inorganic species on silica fouling in RO membranes, Desalination 144 (2002) 373-378.
[20] R. Higgin, K.J. Howe, T.M. Mayer, Synergistic behavior between silica and alginate: novel approach for removing silica scale from RO membranes, Desalination 250 (2010) 76-81.

[21] S.S. Madaeni, T. Mohamamdi, M.K. Moghadam, Chemical cleaning of reverse osmosis membranes, Desalination 134 (2001) 77-82

[22] R. Sheikholeslami, I.S. Al-Mutaz, S. Tan, S.D. Tan, Some aspects of silica polymerization and fouling and its pretreatment by sodium aluminate, lime and soda ash, Desalination 150 (2002) 85-92.

[23] E. Neofotistou, K.D. Demadis, Use of antiscalants for mitigation of silica $\left(\mathrm{SiO}_{2}\right)$ fouling and deposition: fundamentals and applications in desalination systems, Desalination 167 (2004) 257-272.

[24] F.H. Butt, F. Rahman, U. Baduruthamal, Characterization of foulants by autopsy of RO desalination membranes, Desalination 114 (1997) 51-64.

[25] M. Euvrard, L. Hadi, A. Foissy, Influence of PPCA (phosphinopolycarboxylic acid) and DETPMP (diethylenetriaminepentamethylenephosphonic acid) on silica fouling, Desalination 205 (2007) 114-123.

[26] L.Y. Liu, Z.W. Ding, L.J. Chang, R.Y. Ma, Z.R. Yang, Ultrasonic enhancement of membrane-based deoxygenation and simultaneous influence on polymeric hollow fiber membrane, Sep. Purif. Technol. 56 (2007) 133-142.

[27] R. Sanderson, J.X. Li, L.J. Koen, L. Lorenzen, Ultrasonic time-domain reflectometry as a non-destructive instrumental visualization technique to monitor inorganic fouling and cleaning on reverse osmosis membranes, J. Membr. Sci. 207 (2002) 105-117.

[28] J.X. Li, R.D. Sanderson, E.P. Jacobs, Ultrasonic cleaning of nylon microfiltration membranes fouled by Kraft paper mill effluent, J. Membr. Sci. 205 (2002) 247-257.

[29] A. Mirzaie, T. Mohammadi, Effect of ultrasonic waves on flux enhancement in microfiltration of milk, J. Food Eng. 108 (2012) 77-86.

[30] C. Zhua, G.L. Liu, C.S. Cheung, C.W. Leung, Z.C. Zhu, Ultrasonic stimulation on enhancement of air gap membrane distillation, J. Membr. Sci. 161 (1999) 85-93.

[31] M. Cai, S.N. Zhao, H.H. Liang, Mechanisms for the enhancement of ultrafiltration and membrane cleaning by different ultrasonic frequencies, Desalination 263 (2010) $133-138$.

[32] X.H. Li, J.X. Li, J. Wang, H. Wang, B.Q. He, H.W. Zhang, W.S. Guo, H.H. Ngo, Experimental investigation of local flux distribution and fouling behavior in double-end and dead-end submerged hollow fiber membrane modules, J. Membr. Sci. 453 (2014) 18-26.

[33] J.X. Li, R.D. Sanderson, In situ measurement of particle deposition and its removal in microfiltration by ultrasonic time-domain reflectometry, Desalination 146 (2002) 169-175.

[34] A.P. Mairal, A.R. Greenberg, W.B. Krantz, Investigation of membrane fouling and cleaning using ultrasonic time-domain reflectometry, Desalination 130 (2000) 45-60.

[35] T. Kobayashi, T. Kobayashi, Y. Hosaka, N. Fujii, Ultrasound-enhanced membranecleaning processes applied water treatments: influence of sonic frequency on filtration treatments, Ultrasonics 41 (2003) 185-190.

[36] S. Muthukumaran, S. Kentish, S. Lalchandani, M. Ashokkumar, R. Mawson, G.W. Stevens, F. Grieser, The optimisation of ultrasonic cleaning procedures for dairy fouled ultrafiltration membranes, Ultrason. Sonochem. 12 (2005) 29-35.

[37] M.L. Xu, X.H. Wen, X. Huang, Z.Y. Yu, M. Zhu, Mechanisms of membrane fouling controlled by online ultrasound in an anaerobic membrane bioreactor for digestion of waste activated sludge, J. Membr. Sci. 445 (2013) 119-126.

[38] M.L. Xu, X.H. Wen, Z.Y. Yu, Y.S. Li, X. Huang, A hybrid anaerobic membrane bioreactor coupled with online ultrasonic equipment for digestion of waste activated sludge, Bioresour. Technol. 102 (2011) 5617-5625.

[39] M.F.N. Secondes, V. Naddeo, V. Belgiorno, F.B. Jr, Removal of emerging contaminants by simultaneous application of membrane ultrafiltration, activated carbon adsorption, and ultrasound irradiation, J. Hazard. Mater. 264 (2014) 342-349.

[40] S. Muthukumaran, K. Yang A. Seuren, S. Kentish, M. Ashokkumar, G.W. Stevens, F. Grieser, The use of ultrasonic cleaning for ultrafiltration membranes in the dairy industry, Sep. Purif. Technol. 39 (2004) 99-107.

[41] S.R. Gonzalez-Avila, F. Prabowo, A. Kumar, C.D. Ohl, Improved ultrasonic cleaning of membranes with tandem frequency excitation, J. Membr. Sci. 415-416 (2012) 776-783.

[42] C. Loderer, D. Pawelka, W. Vatier, P. Hasal, W. Fuchs, Dynamic filtration-ultrasonic cleaning in a continuous operated filtration process under submerged conditions, Sep. Purif. Technol. 119 (2013) 72-81.

[43] M. Khayet, T. Matsuura, Preparation and characterization of polyvinylidene fluoride membranes for membrane distillation, Ind. Eng. Chem. Res. 40 (2001) 5710-5718.

[44] V. Jafari, A. Allahverdi, M. Vafaei, Ultrasound-assisted synthesis of colloidal nanosilica from silica fume: effect of sonication time on the properties of product, Adv. Powder Technol. 25 (2014) 1571-1577. 